\title{
Modulation of the human sensorimotor system by afferent somatosensory input: evidence from experimental pressure stimulation and physiotherapy
}

\author{
Pavel Hok, Petr Hlustik
}

Peripheral afferent input is critical for human motor control and motor learning. Both skin and deep muscle mechanoreceptors can affect motor behaviour when stimulated. Whereas some modalities such as vibration have been employed for decades to alter cutaneous and proprioceptive input, both experimentally and therapeutically, the central effects of mechanical pressure stimulation have been studied less frequently. This discrepancy is especially striking when considering the limited knowledge of the neurobiological principles of frequently used physiotherapeutic techniques that utilise peripheral stimulation, such as reflex locomotion therapy. Our review of the available literature pertaining to pressure stimulation focused on transcranial magnetic stimulation (TMS) and neuroimaging studies, including both experimental studies in healthy subjects and clinical trials. Our search revealed a limited number of neuroimaging papers related to peripheral pressure stimulation and no evidence of effects on cortical excitability. In general, the majority of imaging studies agreed on the significant involvement of cortical motor areas during the processing of pressure stimulation. Recent data also point to the specific role of subcortical structures, such as putamen or brainstem reticular formation. A thorough comparison of the published results often demonstrated, however, major inconsistencies which are thought to be due to variable stimulation protocols and statistical power. In conclusion, localised peripheral sustained pressure is a potent stimulus inducing changes in cortical activation within sensory and motor areas. Despite historical evidence for modulation of motor behaviour, no direct link can be established based on available fMRI and electrophysiological data. We highlight the limited amount of research devoted to this stimulus modality, emphasise current knowledge gaps, present recent developments in the field and accentuate evidence awaiting replication or confirmation in future neuroimaging and electrophysiological studies.

Key words: somatosensory system, sensorimotor integration, pressure stimulation, neurorehabilitation, Vojta reflex locomotion therapy

Received: March 27, 2020; Revised: September 16, 2020; Accepted: October 27, 2020; Available online: November 13, 2020 https://doi.org/10.5507/bp.2020.052

(c) 2020 The Authors; https://creativecommons.org/licenses/by/4.0/

Department of Neurology, Faculty of Medicine and Dentistry, Palacky University Olomouc, and University Hospital Olomouc, Czech Republic Corresponding author: Pavel Hok, e-mail: pavel.hok@upol.cz

\section{INTRODUCTION}

Peripheral afferent input provides a critical drive for primate motor control and its complete removal (deafferentation) leads to paralysis ${ }^{1}$. Deafferentation in the absence of specific intervention also suppresses motor plasticity and learning ${ }^{2}$. Conversely, long term potentiation-like facilitation of primary motor cortex (M1) neuronal discharge can be demonstrated following direct stimulation of the primary somatosensory cortex (S1) in the mammalian brain ${ }^{3}$. Peripheral afferent stimulation has therefore been used to induce experimental plasticity of the human motor system ${ }^{4}$ and has become an important component of techniques aimed at improving or restoring the motor function ${ }^{5}$. Beyond short-term facilitation of motor responses known since Sherrington ${ }^{6}$, longer duration of peripheral stimulation can induce facilitatory changes that last for minutes and hours ${ }^{7}$. Most frequently studied peripheral stimulation modalities include electrical nerve stimulation or vibration, which are simple to control and administer $^{7-10}$. Natural modalities of peripheral stimulation, such as tactile, pressure or proprioceptive, have been studied less extensively ${ }^{11,12}$, although they represent essential elements of some clinical rehabilitation techniques and procedures ${ }^{13-15}$. Whereas noxious mechanical pressure stimulation has been employed in research of central pain processing ${ }^{16}$, the effects of sustained innocuous pressure have been explored to a lower extent. Even less attention has been paid to the interaction of central somatosensory processing of pressure with the "classical" motor system, but see ref. ${ }^{11,12,17}$.

In this review, we provide an overview of how the sensorimotor system is affected by pressure stimulation motivated by its clinical applications. Since a full overview would be beyond the scope of a single review article, we focus on the central effects of prolonged stimulation. For the same reasons, primarily the evidence from studies using transcranial magnetic stimulation (TMS), functional magnetic resonance imaging (fMRI), and positron emission tomography (PET) is considered. Other selected approaches are discussed where there is a requirement to provide a sufficient background. Finally, we attempt to delineate where the future research interests may lie and suggest directions for follow-up studies. 


\section{SENSORY STRUCTURES RESPONDING TO INNOCUOUS PRESSURE}

The perception of innocuous mechanical skin stimulation, which we focus on in this review, is mediated by the so-called low-threshold mechanoreceptors ${ }^{18}$. These include four types of afferents defined based on their receptive fields and discharge pattern: slow-adapting type I afferents (SA-I, Merkel endings or disks) for static stimuli; slow-adapting type II for skin stretching; fastadapting type I (Meissner endings) detecting flutter up to 40-50 Hz; and fast-adapting type II (Pacinian corpuscles) responding to high-frequency vibratory stimuli up to 400 Hz. Mechanical pressure stimulation primarily excites SA-I afferents which respond to static pressure, as well as low frequency mechanical stimulation (usually below $5 \mathrm{~Hz}$ ) and skin deformation ${ }^{19}$. In microneurographic studies, SA-I endings were also shown to participate in coding joint positions ${ }^{20,21}$, which illustrates their ability to transmit proprioceptive information concerning relative limb positions ${ }^{9}$. Before reaching the cortex, information from cutaneous afferents is already combined with motor efferent signals at multiple levels of the central nervous system, including the spinal cord grey matter, brainstem nuclei and thalamus. For detailed reviews of central projecting pathways and the physiological background of sensorimotor integration at the cortical level see $\mathrm{se}^{9,18,22,23}$.

\section{BEHAVIOURAL EFFECTS OF PERIPHERAL PRESSURE STIMULATION}

The central effects of peripheral pressure stimulation on motor control are best demonstrated by taking a closer look at the phenomena that alter motor behaviour and performance. A rather thorough physiological background is introduced here, as it is crucial for describing the observed behavioural effects as well as for understanding the rationale and correct interpretation of the electrophysiology and imaging studies.

Peripheral mechanical stimulation modalities, such as vibration, have long been known to elicit muscle contraction, overt involuntary tonic and phasic movements, postural sways, and modification of voluntary motor actions during and after the stimulation ${ }^{9,10}$. Similar modulation of motor behaviour, including involuntary motor responses and outlasting motor after-effects, has also been demonstrated after mechanical pressure stimulation ${ }^{24-26}$. It is therefore not surprising that pressure stimulation has been incorporated into a number of physiotherapeutic techniques, such as clinical massage, acupressure ${ }^{13}$, reflexology, or myofascial trigger point therapy ${ }^{14}$. Another example of mechanical pressure stimulation in clinical use is stimulation according to Vojta, i.e., a component of the physiotherapeutic technique also known as reflex locomotion therapy (RLT) or Vojta method ${ }^{15,25-30}$, which is clinically employed in several European ${ }^{31-38}$ and Asian countries $^{39,40}$. Given the lack of comprehensive literature on RLT and its relevance to some published imaging re- search, we provide here a broader historical perspective on this topic.

\section{INVOLUNTARY MOTOR RESPONSES TO PRESSURE STIMULATION}

Inspired by published neurophysiological and clinical studies $^{24,41-46}$ and his own clinical observations ${ }^{26,47}$, Vojta noted that, in several body configurations, sustained manual pressure stimulation of specific points on the skin surface ("stimulus points" or "stimulation/reflex/trigger zones") gradually evokes a widespread motor response (asymmetrical muscle contraction on both sides of the neck, trunk, and limbs). This evoked motor response has been called "reflex locomotion" and involves two basic patterns, "reflex creeping" (also called crawling) - first observed by Bauer ${ }^{24,26}$ - and "reflex turning" (also called rotation or rolling) (ref. ${ }^{25,26,29,30}$ ). These tonic motor responses share certain similarities with other automatisms described in neonates, pre-term infants, human fetuses, and under certain conditions also in healthy adults ${ }^{29,30,48-51}$. Similarly, reflex locomotion is easiest to observe in healthy newborns up to 6 weeks of age ${ }^{29}$, but can also be elicited in children with cerebral palsy, adults with a nervous system injury, as well as in healthy humans upon longer sustained peripheral stimulation of multiple trigger zones (temporal and spatial summation) (ref. ${ }^{15,29,52}$ ).

Apart from evoked involuntary muscle contraction, the further effects of reflex locomotion have been described as well: voluntary movement facilitation, improvement of neurological abnormalities, and autonomic changes ${ }^{15,29,33,34,50,53-56}$. The effects have been observed to last for at least 30 minutes $^{15}$. It was originally speculated that these sequelae of stimulation are mediated by massive, mainly proprioceptive afferentation which accompanies reflex locomotion ${ }^{15,29,50}$. Supported by the published works ${ }^{57-59}$ and his own observations ${ }^{47,60}$, Vojta also emphasized the central role of proprioception in the development of spasticity, as opposed to the mere loss of inhibitory control from higher-order motor centres ${ }^{30,47,50}$.

Despite the decades of clinical use of RLT, there has been limited knowledge of its neurobiological basis, as the available evidence mostly consisted of kinesiology and observation studies ${ }^{15}$. Originally, proprioception has been suggested to dominate the sensory afferentation triggering the motor response $\mathrm{e}^{15,29}$. Indeed, pressure sensation from the foot soles contributes to maintenance of an upright stance $^{61,62}$. It was further emphasized that, in certain cases, the starting body position is essential to elicit the complete motor response ${ }^{29}$. Such posture-dependent involuntary responses were also demonstrated using cutaneous and muscle vibration ${ }^{63,64}$. The efferent pathways mediating reflex locomotion have been speculated to involve an extrapyramidal or parapyramidal system (i.e., bypassing the corticospinal tract), since reflex locomotion is best observed in neonates whose motor cortex is not yet mature ${ }^{29}$. Due to its complex nature involving all the extremities and truncal muscles at the same time, a common coordination 
centre has been suggested ${ }^{29}$. The horizontal gaze deviation, observed during the motor response, indicates that its neural substrate involves a supraspinal, at least upper brainstem structure, including the midbrain reticular formation ${ }^{15,26,29,47,65}$. In fact, the evidence for central pattern generators from animal experimental research suggests the existence of similar structures also in humans, possibly located to the midbrain or neighbouring structures ${ }^{66-68}$. Nevertheless, the frequent observation of partial motor responses limited to one or more extremities additionally suggests the existence of multiple lower-level independent sources of the motor responses ${ }^{15}$. This is again in line with the animal research evidence demonstrating that lowerorder generators of simple locomotion patterns independent for each extremity reside on the spinal level and are under top-down control of higher-order areas ${ }^{68}$. Reflex locomotion has also been contrasted with other primitive reflexes, e.g., "tonic neck reflexes" $25,26,29,45$. Since they can be suppressed by reflex locomotion ${ }^{29}$, the structures responsible for the tonic neck reflexes have therefore been suggested to lie hierarchically lower than those implicated in reflex locomotion, namely in the lower brainstem ${ }^{29}$. At the time of the methodological development of RLT, however, there were no non-invasive human methods available to test these hypotheses.

\section{EVIDENCE FROM ELECTROPHYSIOLOGY STUDIES}

Several studies using electromyographic (EMG) recordings in both animals and humans evaluated the reflex muscle activity during pressure stimulation. In cats, complex tonic reflexes were elicited by short as well as longer maintained pressure applied at the pads ${ }^{69}$, whereas pressure stimulation of the chest modulated posture-dependent muscle activity ${ }^{70}$. In humans, EMG studies demonstrated a gradual and rhythmical motor response during RLT (ref. ${ }^{52}$ ) and confirmed the spatial and temporal summation of these responses ${ }^{71}$. Despite slight inter-individual differences, the order of muscle engagement seems to be relatively constant across subjects ${ }^{31,72}$. Gajewska et al. (ref. ${ }^{31}$ ) suggested that the stereotypic and crossed nature of the observed muscle activations reflected excitation via long propriospinal pathways, but the influence of supraspinal motor centres could not be ruled out.

Currently, there are no non-invasive methods available to directly investigate electrophysiological activity in the brainstem sensorimotor nuclei. Non-invasive assessment of cortical excitability may still provide, however, some indications of changes occurring in cortico-subcortical loops, beyond the cortex itself. Studies employing pairedpulse TMS (ref. ${ }^{73}$ ) have evaluated corticomotor excitability changes due to extended peripheral electrical ${ }^{7}$ and mechanical stimulation ${ }^{74}$ and revealed that longer periods of sustained or repetitive stimulation (up to 2 hours $^{7}$ ) lead to an increase in motor cortical excitability outlasting the stimulation period on the order of several hours. It is likely that sustained pressure stimulation, involving the same cutaneous afferents, would evoke similar changes in cortical excitability. The underlying mechanisms within intracortical circuits potentially involve changes in intracortical inhibition and/or intracortical facilitation as seen in a number of studies using different modalities of peripheral stimulation ${ }^{74-78}$. However, to our knowledge, there are currently no published studies regarding such changes following mechanical pressure.

\section{EVIDENCE FROM FMRI AND PET STUDIES}

The lack of neurophysiological evidence for the central motor effects of peripheral pressure stimulation has been compensated for by an increasing body of neuroimaging research. However, in most of these studies, the relationship between sensory stimulation and motor control has not been purposefully investigated. In this section, we therefore present mostly indirect evidence for sensorimotor integration based on the reported motor cortex co-activations.

A pioneering PET study assessed activation during the discrimination task of the slow-onset yet short pressure stimuli applied to the distal phalanx of the right index finger $^{79}$. Compared to the rest condition, the subjects activated not only primary and association somatosensory and multimodal cortices (the contralateral S1 - Brodmann areas [BA] 3b, 1 and 2, posterior insula and secondary somatosensory cortex [S2], and ipsilateral supramarginal gyrus) but also primary and association motor areas (M1 [BA 4a] and dorsal premotor cortex). The study thus demonstrated the immediate involvement of motor cortices during steady pressure stimulation.

Two fMRI studies evaluated static pressure stimulation applied over the right index fingertip using an air-cuff ${ }^{80,81}$. Stimulation evoked an extensive activation pattern, overlapping but not identical to that described in the above quoted $\left(\right.$ ref. $\left.^{79}\right)$. Somatosensory or multimodal areas included bilateral postcentral gyrus (S1), S2, and insulae, whereas motor areas included the ipsilateral dorsolateral precentral gyrus (M1), and contralateral midcingulate gyrus $^{81}$. Subsequent dynamic causal modelling revealed that the intrahemispheric processing of the pressure stimuli employed both serial (from S1 to S2) and parallel processing in the S1 and S2 (ref. ${ }^{81}$ ). In the follow-up study, Chung et al. ${ }^{80}$ evaluated the temporal evolution of the cortical activation during static sustained pressure stimulation of the index finger tip applied over 3 to $15 \mathrm{~s}$. Overall, they found the most consistent activations again in somatosensory (the contralateral postcentral gyrus [S1], bilateral S2, and insulae) and motor (ipsilateral precentral gyrus [M1] and cingulate cortices) areas as well as the thalami and cerebellum. Notably, they observed that activations differed substantially depending on the duration of the stimulus and the time-window chosen and provided evidence for gradual adaptation of the activated areas to stimulation.

Several studies of sustained pressure finger stimulation reported, however, much less extensive activations restricted to somatosensory areas. Contralateral S1 and supramarginal gyrus activations were observed in a small group of 8 subjects in response to air-cuff sustained 30-s 
pressure applied to one of the four fingers: index, middle, ring, and little finger. Here, the small number of subjects may have resulted in low power to detect motor cortical activation. A multivariate analysis then found that activation in the contralateral supramarginal gyrus encoded the stimulated finger locations (proximal vs. distal) (ref. ${ }^{82}$ ). Another study evaluated the effect of sustained pressure applied via a plastic piston to a thumb in 24 subjects during a working memory n-back task (i.e., during serial presentation of a stimulus spaced several seconds apart requiring maintaining $n$ stimuli in the working memory). No effect on task performance was observed and imaging data revealed pressure-related activation (contrast n-back with pressure vs. n-back without pressure) again only in the contralateral S1 and S2, although motor activations could have been masked by the required button responses $^{83}$.

Several studies also evaluated pressure stimulation applied to the lower limbs. In the first yet still preliminary fMRI study, only limited activation in the primary sensorimotor cortex and bilateral S2 was observed during sustained $1 \mathrm{~Hz}$ sinusoidal pressure stimulation applied for $30 \mathrm{~s}$ to the sole of the foot ${ }^{84}$. In a follow-up fMRI study with twice as many participants (16), sustained right foot sole stimulation evoked more widespread activations in somatosensory (the bilateral postcentral gyrus, bilateral inferior parietal lobules, contralateral insula and superior parietal lobule) as well as motor (bilateral precentral, middle and superior frontal cortices, bilateral cingulate gyrus) areas and in the contralateral temporal cortex ${ }^{85}$. In an even larger sample (30 subjects), Miura et al. ${ }^{86}$ reported more circumscribed activation in the contralateral S1, S2, M1, supplementary motor area, and ipsilateral cerebellum in response to considerably shorter 5-s manual pressure stimuli applied over the base of the toes of either foot.

Further fMRI studies ${ }^{87,88}$ investigated the central correlates of manual pressure applied over the lumbar vertebrae in the prone position. Apart from bilateral activation in the medial S1 and S2, insular and cingulate cortices as well as cerebellum were significantly activated ${ }^{88}$. The roles of cutaneous afferents from the limbs and trunk in motor control, however, may be essentially different.

In summary, non-therapeutic pressure stimulation of the fingers, foot sole, or lower back were mostly associated with somatosensory cortical activity in the S1 and $\mathrm{S} 2$, and in sufficiently powered studies, also with widespread sensorimotor activations including M1, the supplementary motor area, posterior parietal cortices, insulae, and cerebellum. The differences among studies may be related not only to various sample sizes, but also to different stimulus intensities, duration, tactile stimulus properties, attention level, or differences in statistical analysis.

The analytic approach seems to be especially important since Chung et al. ${ }^{80}$ demonstrated that the canonical haemodynamic response function may be insensitive to adapting cortical activations. An intriguing picture emerges when we contrast these results with different stimulation modalities, such as mechanical vibration. The widespread activation pattern, observed in sufficiently powered focal pressure stimulation studies, is consistent with studies using rather broad-area vibrotactile stimulation $^{89,90}$ or muscle stimulation ${ }^{91,92}$ and far exceeds the cortical maps of relatively circumscribed finger vibrotactile stimulation in other studies ${ }^{93-95}$. Although qualitatively different stimuli are not directly comparable, this illustrates that pressure stimulation can be associated with robust motor activations that provide the neuroanatomical substrate for sensorimotor interactions and motor aftereffects of stimulation.

As shown in vibration studies, however, sensorimotor activations are sensitive to modulation by higher-order processes, such as attention and cognitive task demands ${ }^{96}$. This necessitates an adequate control condition, e.g., a comparison between similar kinds of stimulation with or without known motor consequences. Therefore, several functional imaging studies contrasted the effects of therapeutic stimulation according to Vojta ${ }^{25,26}$ with a sham stimulation ${ }^{11,12,17}$. Sanz-Esteban et al. ${ }^{17}$ applied pressure stimulus to an active site at the anterior thorax ${ }^{25}$ and reported the main effect of the stimulation site (active versus control) in the ipsilateral putamen ${ }^{17}$. Due to unbalanced group sizes, a control stimulation site in a distant body part, and uncorrected statistical thresholds, however, the conclusions that can be drawn are substantially limited.

In our fMRI study of sustained manual pressure stimulation $^{12}$, we compared an active lateral heel site at the right foot $^{26}$ to a nearby control lateral ankle site in 30 healthy volunteers who underwent two fMRI sessions according to a cross-over single-blinded randomised study design. To more closely match the characteristic postural conditions and prolonged manual stimulation during RLT (ref. ${ }^{25,26}$ ), pressure was applied manually by an experienced therapist while the subjects were lying in prone position. As we expected considerable adaptation of the blood oxygenation level-dependent (BOLD) response ${ }^{80}$, we have delivered the stimulation in irregularly spaced (jittered) 30-s blocks and utilized a flexible modelling approach using finite impulse response basis functions to capture the dynamics of the BOLD signal during a 45-s time window. Subsequently, a clustering algorithm was employed to classify the individual clusters of the significant signal change based on the shape of the BOLD response and to identify both activations and deactivations associated with the stimulation. Our results demonstrated that stimulation at both sites evoked widespread responses throughout the sensorimotor system. Despite sustained though gradually somewhat decreasing pressure, most of the clusters were characterized only by transient onset and offset responses that could be classified into two anti-correlated sets of areas. Task-positive areas were found in the bilateral S1, $\mathrm{S} 2$, contralateral M1, premotor cortex (dorsomedial part), bilateral thalami, and left prefrontal cortex. Task-negative areas were detected in the bilateral sensorimotor cortices (outside of the task-positive areas), premotor cortex (dorsolateral part), medial occipital cortex (visual cortex), and superior parietal lobule. In fact, some of the transient deactivations in motor representations of non-stimulated limbs could explain apparent motor activations observed in previous studies ${ }^{80,81}$. If stimulated for a sufficiently 
long time, the BOLD response rises again even above the baseline producing a "false" net activation increase. The mechanisms behind deactivations are not yet completely understood. Nevertheless, they should still be considered when interpreting data involving prolonged stimulation ${ }^{12}$.

Our study also demonstrated some specific effects of stimulation according to RLT (ref. ${ }^{12}$ ). The "active" stimulation site was additionally associated with a more sustained task-positive activation in another set of brain areas. These included the bilateral insulo-opercular cortices and contralateral pons. Quantitative differences between the two stimulation types (sites) were also assessed and detected in the contralateral (left) inferior parietal lobule and M1.

Importantly, these differences in the contralateral (left) inferior parietal lobule and M1 were independent of the pain/unpleasantness reported by some subjects. Despite the overall low pain/unpleasantness ratings, they correlated with activation difference in a different cortical area, namely in the contralateral superior parietal lobule ${ }^{12}$. Additionally, our parallel study established that the autonomic nervous system responses do not differ between the two stimulation types ${ }^{97}$. Our imaging data thus demonstrated that manual pressure stimulation affects multiple brain structures involved in motor control and that the choice of stimulation site impacts the shape (insulo-opercular cortices and pons) and amplitude (contralateral M1 and inferior parietal lobule) of the BOLD response in the sensory (insula, inferior parietal lobule) and proper motor areas (M1) (ref. ${ }^{12}$ ).

In our second study ${ }^{11}$, we evaluated the motor sequelae of sustained manual pressure stimulation. Using the same cross-over design, we investigated the changes in brain activation during a complex hand motor task, namely sequential finger opposition. The subjects performed auditory-paced finger opposition with their right hand before and after 20 min of intermittent manual pressure (in total $12 \mathrm{~min}$ on stimulation) applied either to the heel (active site) or ankle (control site). A simple repetition of the motor task, regardless of the intervention site, resulted in a widespread sensorimotor and cross-modal activation decrease, possibly due to motor learning. An analysis of two-way interaction between the stimulation site and repetition revealed an effect in the contralateral pontomedullary reticular formation (PMRF) and bilateral posterior cerebellum. While activation in the $\mathrm{PMRF} /$ cerebellum increased after the heel stimulation, it decreased following sham stimulation at the ankle ${ }^{11}$. PMRF is known to modulate postural control ${ }^{98}$, locomotion $^{99}$, possibly by exerting anticipatory postural control ${ }^{100}$, and even targeted limb movements ${ }^{101}$ or finger movements ${ }^{102}$. It has also been shown to mediate complex asymmetrical motor patterns in mammalian preparations ${ }^{99,102}$ bearing some resemblance to involuntary motor behaviour elicited during RLT (ref. ${ }^{25,26}$ ). As we have also seen involvement of nearby pontine areas during the heel (active) stimulation in the first study ${ }^{12}$, we have speculated that the PMRF may play a role in mediating (some of) the therapeutic effects of RLT (ref. ${ }^{11,12}$ ).

\section{SUMMARY AND FUTURE DIRECTIONS}

The research on the central effects of peripheral pressure stimulation is not as rich and elaborate as, for example, in the case of vibratory stimulation. Nevertheless, available historical, behavioural and clinical studies have indicated similarly complex effects on motor behaviour as in the case of a vibration. In a first attempt to assemble studies potentially shedding some light on the central effects of pressure stimulation, we have reviewed neurophysiological and neuroimaging studies involving pure experimental stimulation and those specifically evaluating stimulation similar to reflex locomotion therapy. The available data, including our own work, clearly demonstrate that stimulation of peripheral pressure-sensitive afferents activates the motor cortical representations and facilitates their short-term neuroplastic changes in the experimental setting. Despite our recent successful efforts to localise some of the central structures potentially involved in motor effects of pressure stimulation, just as many new questions arose as have been answered. The following text lists several outstanding questions and provides suggestions how to approach them in future studies:

Question 1: What is the dynamic evolution of the cortico-subcortical activation patterns during continuous application of specific forms of pressure stimulation, such as RLT?

Suggestion: Given the known slow development of responses ${ }^{26,52,71}$, a time-resolved analysis of the so-called dynamic connectivity ${ }^{103}$ might prove useful for detection of slowly evolving states of brain function and their correlation with behaviour. To make this possible, detailed behavioural and electrophysiological data (EMG), acquired simultaneously with fMRI, are necessary prerequisites since the time-courses of the individual responses may vary significantly across subjects.

Significance: This might help us detect further brain structures which participate in these processes only transiently or whose activity gradually builds up. Such activations might be missed by classical approaches that effectively average the signal change across the entire imaging run ${ }^{103}$.

Question 2: Can we identify the brain structures that mediate the motor improvement?

Suggestion: Follow-up studies with well-defined outcome measures of motor performance, both in healthy controls and patients with motor system disorders, are warranted. Only then may improved performance or alleviated symptoms be directly linked to the involved brain structure.

Significance: This is of paramount importance because such studies could finally draw clinically relevant conclusions, such as predictions of outcomes according to baseline fMRI data. Additionally, by knowing the structures that are related to improvement, we may identify candidates for potential interventions that either enhance the effect of peripheral stimulation or interfere with it, 
such as repetitive TMS or transcranial direct current stimulation, eventually providing real-life causal data.

Question 3: What are the pathways connecting the individual nodes, either those identified as potential sources of involuntary motor behaviour or those associated with motor after-effects (e.g., PMRF in case of RLT)?

Suggestion: By acquiring and evaluating diffusionweighted imaging data, one can identify the connecting pathways between these nodes to establish a task-specific connectome.

Significance: Knowing the cortical area or nuclei engaged by stimulation might not be enough to fully appreciate the brain network(s) underlying the motor after-effects and understand the interactions among the network nodes. With added knowledge of the network topology, modelling of causal relationships (i.e., effective connectivity) would be possible. Accurate network models might then serve as predictors of behavioural and clinical outcomes of various interventions.

Question 4: How should the neuroimaging evidence be interpreted and how can it be linked to the peripheral effects of stimulation?

Suggestion: Effects of pressure stimulation on corticomotor excitability should also be studied using transcranial magnetic stimulation or similar methods evaluating the function of the corticospinal tract. Knowing that muscle vibration research has demonstrated divergent results in different muscle groups ${ }^{10,78}$ and study populations ${ }^{104}$, multiple stimulation sites and patient cohorts with evidence of abnormal sensorimotor processing, such as dystonia ${ }^{104}$, should be considered. In addition, patient populations, where RLT is routinely applied to alleviate neurological abnormalities (e.g., spasticity after stroke or in multiple sclerosis ${ }^{36}$ ), would be candidates for studies correlating possible clinical improvement with cortical excitability changes.

Significance: Although electrophysiological techniques lack the spatial resolution of current imaging methods, they provide an important link between the processes occurring in the central nervous system and their peripheral manifestations.

\section{CONCLUSION}

In summary, pressure stimulation is a viable and widely used modality of peripheral stimulation in the clinical setting. Whereas other stimulation modalities, such as vibration, have already attracted a high amount of research interest and much evidence has been now gathered using state-of-the-art imaging techniques, allowing researchers to postulate fairly concrete hypotheses, similar research on pressure stimulation has barely entered the initial exploratory stage. We have highlighted recent evidence demonstrating the involvement of brainstem and cortical structures that potentially mediate some of the peculiar effects observed during sustained mechanical pressure stim- ulation. Inspired by the latest development, we propose future directions to shed more light on these phenomena.

\section{Search strategy and selection criteria}

Our review of the available literature pertaining to innocuous pressure stimulation focused on TMS and neuroimaging studies including both human experimental studies in healthy subjects and clinical trials as well as secondary sources. Scientific articles from 1950 to 2020 were searched using the PubMed and Web of Science databases, the results were up to date as of March 2020. The main search terms used included '(PET OR fMRI) AND (skin OR cutaneous OR peripheral OR manual OR tactile) AND ("pressure stimulation" OR ("tactile stimulation” AND pressure))'; 'TMS AND (skin OR cutaneous OR peripheral OR manual OR tactile) AND ("pressure stimulation" OR ("tactile stimulation" AND pressure))"; '("Vojta therapy" OR "Vojta physiotherapy" OR "reflex locomotion" OR "Vojta method" OR "Vojta") AND (PET OR fMRI)'; and '("Vojta therapy" OR "Vojta physiotherapy" OR "reflex locomotion" OR "Vojta method" OR "Vojta") AND TMS'. Both full terms and abbreviations were searched. After the search, abstracts were screened for inclusion criteria, following a thorough full-text screening of matching papers for exclusion criteria. Inclusion criteria: all original and review papers involving somatosensory skin stimulation of human subjects evaluated using PET, fMRI or TMS written in English and matching search criteria. Exclusion criteria: insufficient reporting of the results, i.e., fMRI studies not reporting activation maps, and non-relevance, i.e., studies not involving deep pressure stimulation, i.e., investigating only non-pressure (superficial) tactile or noxious pressure stimulation. To provide a historical perspective, non-English literature on reflex locomotion therapy was included, whereas the database search only considered English language original research papers and reviews. Relevant secondary cited sources were included as well.

The database search yielded 14 unique results for the fMRI/PET studies (PubMed and Web of Science combined), but returned no papers using TMS matching the search criteria. Out of the 14 identified papers, 10 were included for a detailed methodological screening, whereas the remaining 4 papers either did not involve any fMRI/ PET assessment (2) or involved no skin stimulation (2). After the detailed assessment, 3 studies were excluded, 2 for not reporting any fMRI/PET activation map, 1 for not involving any innocuous stimulation. None of the imaging studies involved PET imaging. Thus, the final sample consisted of $7 \mathrm{fMRI}$ studies. The remaining studies were identified as secondary sources.

\section{ABBREVIATIONS}

BA, Brodmann area; BOLD, Blood oxygenation leveldependent; EMG, Electromyography; fMRI, Functional magnetic resonance imaging; M1, Primary motor cortex; PET, Positron emission tomography; PMRF, 
Pontomedullary reticular formation; RLT, Reflex locomotion therapy; S1, Primary somatosensory cortex; S2, Secondary somatosensory cortex; SA-I, Slow-adapting type I afferents; TMS, Transcranial magnetic stimulation.

Acknowledgement: This work was supported by the Czech Science Foundation (GACR) (Grant No. 14-22572S), and Ministry of Health, the Czech Republic (Grant No. NV17-29452A and conceptual development of research organization No. FNO1, 00098892).

Author contributions: PHo: literature search, manuscript writing and revision; $\mathrm{PHl}$ : conception and design of the work, manuscript writing and revision. Both authors have read and approved the final version of the manuscript.

Conflict of interest statement: The authors state that there are no conflicts of interest regarding the publication of this article.

\section{REFERENCES}

1. Mott FW, Sherrington CS. Experiments upon the influence of sensory nerves upon movement and nutrition of the limbs. Preliminary communication. Proc R Soc Lond 1895;57(340-346):481-8.

2. Pavlides $C$, Miyashita $E$, Asanuma $H$. Projection from the sensory to the motor cortex is important in learning motor skills in the monkey. J Neurophysiol 1993;70(2):733-41.

3. Sakamoto T, Porter LL, Asanuma H. Long-lasting potentiation of synaptic potentials in the motor cortex produced by stimulation of the sensory cortex in the cat: a basis of motor learning. Brain Res 1987;413(2):360-4

4. Ridding MC, McKay DR, Thompson PD, Miles TS. Changes in corticomotor representations induced by prolonged peripheral nerve stimulation in humans. Clin Neurophysiol 2001;112(8):1461-9.

5. Powell J, Pandyan AD, Granat M, Cameron M, Stott DJ. Electrical stimulation of wrist extensors in poststroke hemiplegia. Stroke 1999;30(7):1384-9.

6. Sherrington CS. Lecture II: Co-ordination in the simple reflex (continued). In: Integr. Action Nerv. Syst. New Haven, CT, US: Yale University Press; 1906;36-69.

7. Chipchase LS, Schabrun SM, Hodges PW. Peripheral electrical stimulation to induce cortical plasticity: a systematic review of stimulus parameters. Clin Neurophysiol 2011;122(3):456-63.

8. Proske U, Gandevia SC. Kinesthetic Senses. Compr Physiol 2018;8(3):1157-83.

9. Proske U, Gandevia SC. The proprioceptive senses: their roles in signaling body shape, body position and movement, and muscle force. Physiol Rev 2012;92(4):1651-97.

10. Souron R, Besson T, Millet GY, Lapole T. Acute and chronic neuromuscular adaptations to local vibration training. Eur J Appl Physiol 2017;117(10):1939-64.

11. Hok P, Opavský J, Kutín M, Tüdös Z, Kaňovský P, Hluštík P. Modulation of the sensorimotor system by sustained manual pressure stimulation. Neuroscience 2017;348:11-22.

12. Hok P, Opavský J, Labounek R, Kutín $M$, Šlachtová $M$, Tüdös $Z$ Kaňovský P, Hluštík P. Differential Effects of Sustained Manual Pressure Stimulation According to Site of Action. Front Neurosci 2019;13:722

13. Wong JJ, Shearer HM, Mior S, Jacobs C, Côté P, Randhawa K, Yu H, Southerst D, Varatharajan S, Sutton D, van der Velde G, Carroll LJ, Ameis A, Ammendolia C, Brison R, Nordin M, Stupar M, Taylor-Vaisey A. Are manual therapies, passive physical modalities, or acupuncture effective for the management of patients with whiplash-associated disorders or neck pain and associated disorders? An update of the Bone and Joint Decade Task Force on Neck Pain and Its Associated Disorders by the OPTIMa collaboration. Spine J Off J North Am Spine Soc 2016;16(12):1598-630.

14. Smith CA, Levett KM, Collins CT, Dahlen HG, Ee CC, Suganuma M Massage, reflexology and other manual methods for pain management in labour. Cochrane Database Syst Rev 2018;3:CD009290.
15. Vojta V, Peters A. Das Vojta-Prinzip: Muskelspiele in Reflexfortbewegung und motorischer Ontogenese. 3., vollst. überarb. Aufl. Berlin: Springer; 2007.

16. Baliki MN, Apkarian AV. Nociception, Pain, Negative Moods, and Behavior Selection. Neuron 2015;87(3):474-91.

17. Sanz-Esteban I, Calvo-Lobo C, Ríos-Lago M, Álvarez-Linera J, MuñozGarcía D, Rodríguez-Sanz D. Mapping the human brain during a specific Vojta's tactile input: the ipsilateral putamen's role. Medicine (Baltimore) 2018;97(13):e0253.

18. Abraira VE, Ginty DD. The sensory neurons of touch. Neuron 2013;79(4):618-39.

19. Johansson RS, Flanagan JR. Coding and use of tactile signals from the fingertips in object manipulation tasks. Nat Rev Neurosci 2009;10(5):345-59.

20. Aimonetti J-M, Hospod V, Roll J-P, Ribot-Ciscar E. Cutaneous afferents provide a neuronal population vector that encodes the orientation of human ankle movements. J Physiol 2007;580(Pt 2):649-58.

21. Edin BB, Abbs JH. Finger movement responses of cutaneous mechanoreceptors in the dorsal skin of the human hand. J Neurophysiol 1991;65(3):657-70.

22. McGlone F, Reilly D. The cutaneous sensory system. Neurosc Biobehav Rev 2010;34(2):148-59.

23. Omrani M, Kaufman MT, Hatsopoulos NG, Cheney PD. Perspectives on classical controversies about the motor cortex. J Neurophysiol 2017;118(3):1828-48.

24. Bauer J. Das Kriechphänomen des Neugeborenen. J Mol Med 1926;5(32):1468.

25. Vojta V. Reflex rotation as a pathway to human locomotion. Z Für Orthop Ihre Grenzgeb 1970;108(3):446-52.

26. Vojta V. Reflex creeping as an early rehabilitation programme. Z Für Kinderheilkd 1968;104(4):319-30.

27. Bauer H, Appaji G, Mundt D. VOJTA neurophysiologic therapy. Indian J Pediatr 1992;59(1):37-51.

28. Vojta V. The basic elements of treatment according to Vojta. In: Manag. Mot. Disord. Child. Cereb. Palsy. Cambridge University Press; 1984;75-85.

29. Vojta V. Early diagnosis and therapy of cerebral movement disorders in childhood. C. Reflexogenous locomotion - reflex creeping and reflex turning. $\mathrm{C} 1$. The kinesiologic content and connection with the tonic neck reflexes. Z Für Orthop Ihre Grenzgeb 1973;111(3):268-91.

30. Vojta V. Plazení v rehabilitaci hybných poruch u dětí. Českoslov Neurol Neurochir Časopis Neurol Spol 1966;29(4):234-9. (In Czech)

31. Gajewska E, Huber J, Kulczyk A, Lipiec J, Sobieska M. An attempt to explain the Vojta therapy mechanism of action using the surface polyelectromyography in healthy subjects: A pilot study. J Bodyw Mov Ther 2018;22(2):287-92.

32. Giannantonio $C$, Papacci $P$, Ciarniello R, Tesfagabir MG, Purcaro V Cota F, Semeraro CM, Romagnoli C. Chest physiotherapy in preterm infants with lung diseases. Ital J Pediatr 2010;36:65.

33. Juárez-Albuixech ML, Redondo-González O, Tello I, Collado-Vázquez S, Jiménez-Antona C. Vojta Therapy versus transcutaneous electrical nerve stimulation for lumbosciatica syndrome: A quasi-experimental pilot study. J Bodyw Mov Ther 2020;24(1):39-46.

34. Jung MW, Landenberger $M$, Jung $T$, Lindenthal T, Philippi $H$. Vojta therapy and neurodevelopmental treatment in children with infantile postural asymmetry: a randomised controlled trial. J Phys Ther Sci 2017;29(2):301-6.

35. Kiebzak W, Kowalski IM, Domagalska M, Szopa A, Dwornik M, Kujawa J, Stępień A, Śliwiński Z. Assessment of visual perception in adolescents with a history of central coordination disorder in early life - 15-year follow-up study. Arch Med Sci AMS 2012;8(5):879-85.

36. Laufens G, Poltz W, Prinz E, Reimann G, Schmiegelt F. Alternating treadmill-Vojta-treadmill-therapy in patients with multiple sclerosis with severely affected gait. Phys Med Rehabil Kurortmed 2004;14(3):134-9.

37. Meholjić-Fetahović A. Treatment of the spasticity in children with cerebral palsy. Bosn J Basic Med Sci Udruženje Basičnih Med Znan Assoc Basic Med Sci 2007;7(4):363-7.

38. Pavlikova M, Cattaneo D, Jonsdottir J, Gervasoni E, Stetkarova I, Angelova G, Markova M, Prochazkova M, Prokopiusova T, Hruskova N, Reznickova J, Zimova D, Spanhelova S, Rasova K. The impact of balance specific physiotherapy, intensity of therapy and disability on static and dynamic balance in people with multiple sclerosis: A multi-center prospective study. Mult Scler Relat Disord 2020:40:101974. 
39. Kanda T, Pidcock FS, Hayakawa K, Yamori Y, Shikata Y. Motor outcome differences between two groups of children with spastic diplegia who received different intensities of early onset physiotherapy followed for 5 years. Brain Dev 2004;26(2):118-26.

40. Lim H, Kim T. Effects of vojta therapy on gait of children with spastic diplegia. J Phys Ther Sci 2013;25(12):1605-8.

41. Bobath $\mathrm{K}$. The effect of treatment by reflex-inhibition and facilitation of movement in cerebral palsy. Folia Psychiatr Neurol Neurochir Neerlandica 1959;62:448-57.

42. Fay T. Rehabilitation of patients with spastic paralysis. J Int Coll Surg 1954;22(2:1):200-3

43. Fay T. The use of pathological and unlocking reflexes in the rehabilitation of spastics. Am J Phys Med 1954;33(6):347-52.

44. Kabat H. 12. Proprioceptive Facilitation. In: Ther. Exerc. Baltimore: Waverly Press; 1958.

45. Magnus R, de Kleijn A. Die Abhängigkeit des Tonus der Extremitätenmuskeln von der Kopfstellung. Pflüg Arch Eur J Physio 1912;145(10):455-548.

46. Peiper A. Die Eigenart der kindlichen Hirntätigkeit. Leipzig: Thieme; 1956.

47. Vojta V. Reflex inhibition of spasticity in perinatal encephalopathy by means of voluntary movement using ontogenetically old structural movements. Ceskoslovenská Neurol 1964;27:329-40.

48. Hellebrandt FAMD, Schade MMS, Carns MLMD. Methods of evok ing the tonic neck reflexes in normal human subjects. J Phys Med 1962;41(3):90-139.

49. Hooker D. The Origin of the Grasping Movement in Man. Proc Am Philos Soc 1938;(4):597.

50. Vojta V. Early diagnosis and therapy of cerebral motor disorders in childhood. A. Postural reflexes in developmental kinesiology. 3 Pathological reflexes from the aspects of tonic neck reflexes and tonic labyrinthine reflexes. Z Für Orthop Ihre Grenzgeb 1972;110(4):46776.

51. Zafeiriou DI. Primitive reflexes and postural reactions in the neurodevelopmental examination. Pediatr Neurol 2004;31(1):1-8.

52. Bauer H, van de Lint A, Soerjanto R, Vojta V. Kinesiologische EMGUntersuchung bei Zerebralparese-Reflexlokomotion nach Vojta. In: Weinmann H-M, ed. Aktuelle Neuropädiatr. 1988. 1st ed.Berlin: Springer; 1988;182-5.

53. Bauer H, Vojta V. Rehabilitation in meningomyelodysplasias. Monatsschrift Für Kinderheilkd 1979;127(5):351-3.

54. Laufens G, Poltz W, Jugelt E, Prinz E, Reimann G, Van Slobbe T. Motor improvements in multiple-sclerosis patients by Vojta physiotherapy and the influence of treatment positions. Phys Med Rehabi Kurortmed 1995;5(4):115-9.

55. Tomi M. Zur Früherkennung und Frühbehandlung bei Kindern mit cerebralen Bewegungsstörungen in Japan. In Entwicklungsrehabilitation Behindertenhilfe Jpn. Bundesrepub. Dtschl. Lübeck: Hansisches Verlagskontor; 1985;35-52.

56. Vojta V. Early diagnosis and therapy of cerebral movement disorders in childhood. C. Reflexogenous locomotion - reflex creeping and reflex turning. C2. Its use in 207 risk children. Analysis of the final results. Z Für Orthop Ihre Grenzgeb 1973;111(3):292-309.

57. Fulton JF. Physiology of the nervous system. New York: Oxford Univ. Press; 1949.

58. Rushworth G. The Nature of the Functional Disorder in the Hypertonic States. Cereb Palsy Bull 1959;1(7):3-7.

59. Windle WF. An experimental approach to prevention or reduction of the brain damage of birth asphyxia. Dev Med Child Neurol 1966;8(2):129-40.

60. Vojta V. Rehabilitation of the spastic infantile syndrome. Personal methodology. Beitr Zur Orthop Traumatol 1965;12(9):557-62.

61. Kavounoudias A, Roll R, Roll JP. Foot sole and ankle muscle inputs contribute jointly to human erect posture regulation. J Physio 2001;532(Pt 3):869-78.

62. Rasman BG, Forbes PA, Tisserand R, Blouin JS. Sensorimotor Manipulations of the Balance Control Loop-Beyond Imposed External Perturbations. Front Neurol 2018;9.

63. Gurfinkel VS, Levik YuS, Kazennikov OV, Selionov VA. Locomotorlike movements evoked by leg muscle vibration in humans. Eur J Neurosci 1998;10(5):1608-12.

64. Smetanin BN, Popov KY, Shlykov VY. Postural responses to vibrostimulation of the neck muscle proprioceptors in man. Neurophysiology 1993;25(2):86-92.
65. Vojta V. Early diagnosis and therapy of cerebral motor disorders in childhood. A. Postural reflexes in developmental kinesiology. 2. Pathologic reactions. Z Für Orthop Ihre Grenzgeb 1972;110(4):45866.

66. Grillner S. Locomotion in vertebrates: central mechanisms and reflex interaction. Physiol Rev 1975;55(2):247-304.

67. Grillner S, Wallén P. Central pattern generators for locomotion, with special reference to vertebrates. Annu Rev Neurosci 1985;8:233-61.

68. Laufens G, Seitz S, Staenicke G. Vergleichend biologische Grundlagen zur angeborenen Lokomotion insbesondere zum"reflektorischen Kriechen" nach Vojta. Krankengymnast Z Für Physiother 1991;43(5):448-56.

69. Hongo T, Kudo N, Oguni E, Yoshida K. Spatial patterns of reflex evoked by pressure stimulation of the foot pads in cats. J Physiol 1990;420:471-87.

70. D'Ascanio P, Gahéry Y, Pompeiano O, Stampacchia G. Effects of pressure stimulation of the body surface on posture and vestibulospinal reflexes. Arch Ital Biol 1986;124(1):43-63.

71. Laufens G, Poltz W, Reimann G, Seitz S. Physiological mechanisms in Vojta-physiotherapy for MS-patients. Phys Med Rehabil Kurortmed 1994;4(1):1-4.

72. Čemusová J, Pánek D, Pavlů D. Možnosti propojení aktivního a pasivního př́stupu ve fyzioterapii. Rehabil Fyzikální Lékařství 2011;18(4):161-6.

73. Kujirai T, Caramia MD, Rothwell JC, Day BL, Thompson PD, Ferbert A, Wroe S, Asselman P, Marsden CD. Corticocortical inhibition in human motor cortex. J Physiol 1993;471:501-19.

74. Christova M, Rafolt D, Golaszewski S, Gallasch E. Outlasting corticomotor excitability changes induced by $25 \mathrm{~Hz}$ whole-hand mechanical stimulation. Eur J Appl Physiol 2011;111(12):3051-9.

75. Golaszewski SM, Bergmann J, Christova M, Kunz AB, Kronbichler M, Rafolt D, Gallasch E, Staffen W, Trinka E, Nardone R. Modulation of motor cortex excitability by different levels of whole-hand afferent electrical stimulation. Clin Neurophysiol Off J Int Fed Clin Neurophysiol 2012;123(1):193-9.

76. Golaszewski SM, Bergmann J, Christova M, Nardone R, Kronbichler M, Rafolt D, Gallasch E, Staffen W, Ladurner G, Beisteiner R. Increased motor cortical excitability after whole-hand electrical stimulation: a TMS study. Clin Neurophysiol Off J Int Fed Clin Neurophysiol 2010;121(2):248-54.

77. Ridding MC, Rothwell JC. Afferent input and cortical organisation: a study with magnetic stimulation. Exp Brain Res 1999;126(4):536-44.

78. Rosenkranz K, Rothwell JC. Differences between the effects of three plasticity inducing protocols on the organization of the human motor cortex. Eur J Neurosci 2006;23(3):822-9.

79. Bodegård A, Geyer S, Herath P, Grefkes C, Zilles K, Roland PE. Somatosensory areas engaged during discrimination of steady pressure, spring strength, and kinesthesia. Hum Brain Mapp 2003;20(2):103-15.

80. Chung YG, Han SW, Kim HS, Chung SC, Park JY, Wallraven C, Kim SP. Adaptation of cortical activity to sustained pressure stimulation on the fingertip. BMC Neurosci 2015;16:71.

81. Chung YG, Han SW, Kim HS, Chung SC, Park JY, Wallraven C, Kim SP. Intra- and inter-hemispheric effective connectivity in the human somatosensory cortex during pressure stimulation. BMC Neurosci 2014;15:43.

82. Kim J, Chung YG, Chung SC, Bülthoff HH, Kim SP. Decoding pressure stimulation locations on the fingers from human neural activation patterns. Neuroreport 2016;27(16):1232-6.

83. Dehghan Nayyeri M, Burgmer M, Pfleiderer B. Impact of pressure as a tactile stimulus on working memory in healthy participants. PloS One 2019;14(3):e0213070.

84. Hao Y, Manor B, Liu J, Zhang K, Chai Y, Lipsitz L, Peng CK, Novak V, Wang $X$, Zhang J, Fang J. A Novel MRI-compatible Tactile Stimulator for Cortical Mapping of Foot Sole Pressure Stimuli with fMRI. Magn Reson Med Off J Soc Magn Reson Med Soc Magn Reson Med 2013;69(4):1194-9.

85. Wang Y, Hao Y, Zhou J, Fried PJ, Wang X, Zhang J, Fang J, PascualLeone A, Manor B. Direct current stimulation over the human sensorimotor cortex modulates the brain's hemodynamic response to tactile stimulation. Eur J Neurosci 2015;42(3):1933-40.

86. Miura N, Akitsuki Y, Sekiguchi A, Kawashima R. Activity in the primary somatosensory cortex induced by reflexological stimulation is un- 
affected by pseudo-information: a functional magnetic resonance imaging study. BMC Complement Altern Med 2013;13:114.

87. Boendermaker B, Meier ML, Luechinger R, Humphreys BK, HotzBoendermaker $\mathrm{S}$. The cortical and cerebellar representation of the lumbar spine. Hum Brain Mapp 2014;35(8):3962-71.

88. Meier ML, Hotz-Boendermaker S, Boendermaker B, Luechinger R Humphreys BK. Neural responses of posterior to anterior movement on lumbar vertebrae: a functional magnetic resonance imaging study. J Manipulative Physiol Ther 2014;37(1):32-41.

89. Golaszewski SM, Siedentopf CM, Koppelstaetter F, Fend M, Ischebeck A, Gonzalez-Felipe V, Haala I, Struhal W, Mottaghy FM, Gallasch E, Felber SR, Gerstenbrand F. Human brain structures related to plantar vibrotactile stimulation: a functional magnetic resonance imaging study. Neurolmage 2006;29(3):923-9.

90. Siedentopf CM, Heubach K, Ischebeck A, Gallasch E, Fend M, Mottaghy FM, Koppelstaetter F, Haala IA, Krause BJ, Felber S, Gerstenbrand F, Golaszewski SM. Variability of BOLD response evoked by foot vibrotactile stimulation: influence of vibration amplitude and stimulus waveform. Neurolmage 2008;41(2):504-10.

91. Naito E, Nakashima T, Kito T, Aramaki Y, Okada T, Sadato N. Human limb-specific and non-limb-specific brain representations during kinesthetic illusory movements of the upper and lower extremities. Eur J Neurosci 2007;25(11):3476-87.

92. Naito E, Roland PE, Grefkes C, Choi HJ, Eickhoff S, Geyer S, Zilles K, Ehrsson HH. Dominance of the right hemisphere and role of area 2 in human kinesthesia. J Neurophysiol 2005;93(2):1020-34.

93. Francis ST, Kelly EF, Bowtell R, Dunseath WJR, Folger SE, McGlone F. fMRI of the Responses to Vibratory Stimulation of Digit Tips. Neurolmage 2000;11(3):188-202.

94. Gelnar PA, Krauss BR, Szeverenyi NM, Apkarian AV. Fingertip representation in the human somatosensory cortex: an fMRI study. Neurolmage 1998;7(4 Pt 1):261-83.
95. Kim J, Chung YG, Chung SC, Bulthoff HH, Kim S-P. Neural Categorization of Vibrotactile Frequency in Flutter and Vibration Stimulations: An fMRI Study. IEEE Trans Haptics 2016;9(4):455-64.

96. Albanese MC, Duerden EG, Bohotin V, Rainville P, Duncan GH Differential effects of cognitive demand on human cortical activation associated with vibrotactile stimulation. J Neurophysio 2009;102(3):1623-31.

97. Opavský J, Šlachtová M, Kutín M, Hok P, Uhliř P, Opavská H, Hluštík P. The effects of sustained manual pressure stimulation according to Vojta Therapy on heart rate variability. Biomed Pap Med Fac Univ Palacky Olomouc Czechoslov 2018;162(3):206-11.

98. Stapley PJ, Drew T. The Pontomedullary Reticular Formation Contributes to the Compensatory Postural Responses Observed Following Removal of the Support Surface in the Standing Cat. J Neurophysiol 2009;101(3):1334-50.

99. Dyson KS, Miron JP, Drew T. Differential modulation of descending signals from the reticulospinal system during reaching and locomotion. J Neurophysiol 2014;112(10):2505-28.

100. Takakusaki K. Neurophysiology of gait: From the spinal cord to the frontal lobe. Mov Disord 2013;28(11):1483-91.

101. Schepens B, Drew T. Independent and convergent signals from the pontomedullary reticular formation contribute to the control of posture and movement during reaching in the cat. J Neurophysio 2004;92(4):2217-38.

102. Hirschauer TJ, Buford JA. Bilateral force transients in the upper limbs evoked by single-pulse microstimulation in the pontomedullary reticular formation. J Neurophysiol 2015;113(7):2592-604.

103. Calhoun VD, Miller R, Pearlson G, Adalı T. The chronnectome: timevarying connectivity networks as the next frontier in fMRI data discovery. Neuron 2014;84(2):262-74.

104. Rosenkranz K, Williamon A, Butler K, Cordivari C, Lees AJ, Rothwell $J C$. Pathophysiological differences between musician's dystonia and writer's cramp. Brain J Neurol 2005;128(Pt 4):918-31. 